\title{
Where Do We Grow from Here? Assessing the Impact of a Digital Media Commons on Student Success
}

\author{
Armondo C. Collins and Kathryn M. Crowe \\ University of North Carolina at Greensboro, USA
}

Assessing the impact of library spaces and instructional support services on student success is a fraught task for many reasons. "What is student success?" "How do we measure it?" "What objectives are driving the data collection process?" and "How will the data collected be used?" are all questions that foreground any attempt at measuring the correlation between a library space or service and a student's successful matriculation. But, as fraught with risk as the process of measuring that correlation may be, assessment is a necessary component for charting the growth and institutional effectiveness of any program, space, or service offered to a modern library user, especially in the fiscally conservative arena of academic libraries. ${ }^{1}$ In our case, we must measure the University of North Carolina at Greensboro's Digital Media Commons (DMC) to chart a path for its growth. For this study, we are not drawing a direct correlation between library instruction and/or use with student grades or retention statistics. Instead, this study seeks to gauge perceived user experiences, taking a patron-driven approach to planning and pedagogy. Approaching its seventh year of existence, the DMC must respond to the rapidly changing instructional environment for which we originally hoped the space and service would be an innovative intervention. The paper presented here is an assessment project conducted to measure patron perceptions of the effectiveness of the DMC's space, instructional support, and customer service performance for the academic years 2017-18 and 2018-19. This mixedmethods study uses qualitative and quantitative data to measure user experience, the perceived value of our service and its impact on our patrons, and the effectiveness of our teaching model in relationship to professors' desired student learning outcomes. The assessment tools used to measure the DMC's effectiveness were: a faculty survey administered during the 2017-18 academic year, a customer service survey administered directly to DMC patrons during the spring and fall semesters of 2018, and two student focus groups facilitated fall 2018. The results garnered from this study will help us improve our users' experience and chart future space and facilities planning. What follows is an overview of the mission and history of the Digital Media Commons that will provide context for this assessment project, followed by a presentation of the results for each measurement studied. This article will conclude with a summary of our preliminary findings along with suggestions for future research and program development.

\section{Background for Study}

The DMC is an instructional support service and digital technology commons located in Jackson Library at UNCG. Charged with a mission to provide space and access to digital composition resources for university users across campus, the DMC supports its broad mission and patron base by providing space, technology, and expertise for creative activities including greenscreen filming, studio photography, podcasting, and 3D scanning and modeling. The DMC also checks out digital production technology, provides individual and group instruction on how to use and choose digital composing technologies, and provides face-to-face troubleshooting assistance for some of the most commonly used digital composing software products in academia.

The DMC was opened in 2012 and was originally conceived of the year prior as a collaboration between the University Libraries and the Multiliteracy Centers then operated by the now defunct Communications Across the Curriculum (CAC) Program at our university. ${ }^{2}$ A survey of students conducted in 2010 indicated that, although they often had assignments requiring videos and other media, there was no support on campus to assist them. The University Libraries provided the space, technology, and staffing for a digital technology center (now known as the DMC) and CAC provided staff and technology for a digital literacy center (now known as the Digital ACT [Action, Consultation, and Training] Studio or DACTS). The library's digital technology center was to provide functional literacy ("how-to") assistance and access to emerging digital design technologies, and the digital literacy center would provide rhetorical and critical literacy ("how does this look?”) feedback consultations to university users engaging with technology as academic users. 
Together, these two services, open to all students, faculty, and staff on campus, were supposed to use the DMC to help UNCG become more effective digital composers. This two-pronged approach envisioned Selber's ${ }^{3}$ functional, critical, and rhetorical literacies as two separate services that needed the same physical space to operate but could use two entirely separate service models to do so. The problems engendered by this oversimplified initial plan were written about by multiple authors and partially remedied by a space redesign in 2015 that gave the digital literacy center space to brand itself separately, and foregrounded writing and digital studio pedagogy into its design and programmatic service model. ${ }^{4}$ The 2015 renovation also allowed the DMC to add two new active learning spaces to its existing footprint and explore the pedagogy of making through its service offerings. ${ }^{5}$

Since this 2015 renovation, DMC service activities have expanded dramatically and there is much to be learned from that transition. The DMC's workshop offerings have expanded with the introduction of 3D making and production workspace to the department. Since its opening day, the DMC has operated on a patron-driven service model that has created a responsive learning environment and work-culture for UNCG patrons. In the past, we conducted an unpublished self-study by a library graduate assistant, ${ }^{6}$ given students pre- and post- workshop surveys, conducted patron focus groups, solicited faculty surveys, and used desk statistics to chart our path. This study, however, is the first effort to assess thoroughly to determine the impact of the Digital Media Commons on student success and improve it as a space and instructional support service focused on digital literacy. The data will be used to align the DMC with the university library's developing master space plan and coordinate the department's instructional support efforts with the library's broader information and digital literacy initiatives. The data presented here may also be useful to peer institutions and researchers interested in assessing active learning spaces focused on digital literacy and instructional technology.

\section{Faculty Survey}

The assessment began with a survey of faculty who had brought their classes to the DMC for instruction in fall 2017 or spring 2018. The survey sought to determine what kind(s) of projects they assigned to their class and the learning goals of the project, if the project met their expectations, and their satisfaction with the instruction session. It then asked if they recommended or required their students to follow up in the DMC by using equipment spaces or scheduling a consultation with staff and if they would use the DMC services again.

The survey was sent to a total of 28 instructors and 12 responded. Results indicate a variety of types of projects, with presentations and videos being the most common:

\section{What type of media was required for the assignment?}

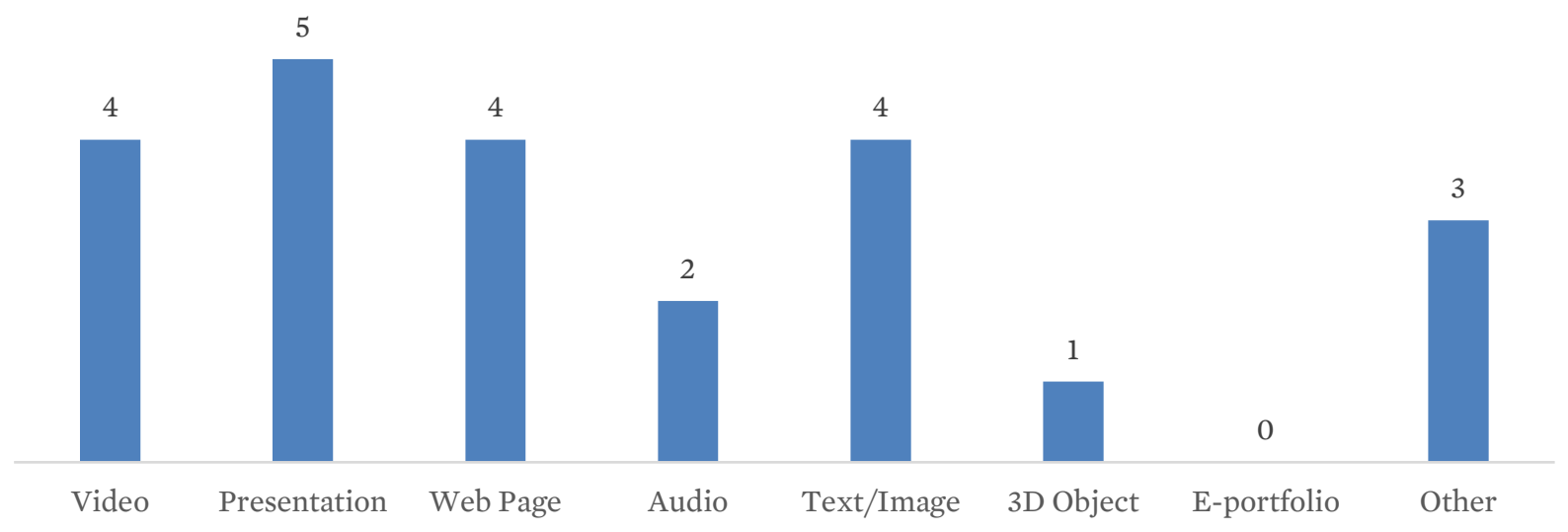


Response to the question about requiring or recommending follow-up from DMC staff or using the equipment indicates that most recommend a consultation and do not often suggest other services.

\section{What type of follow-up did you recommend or require from students?}

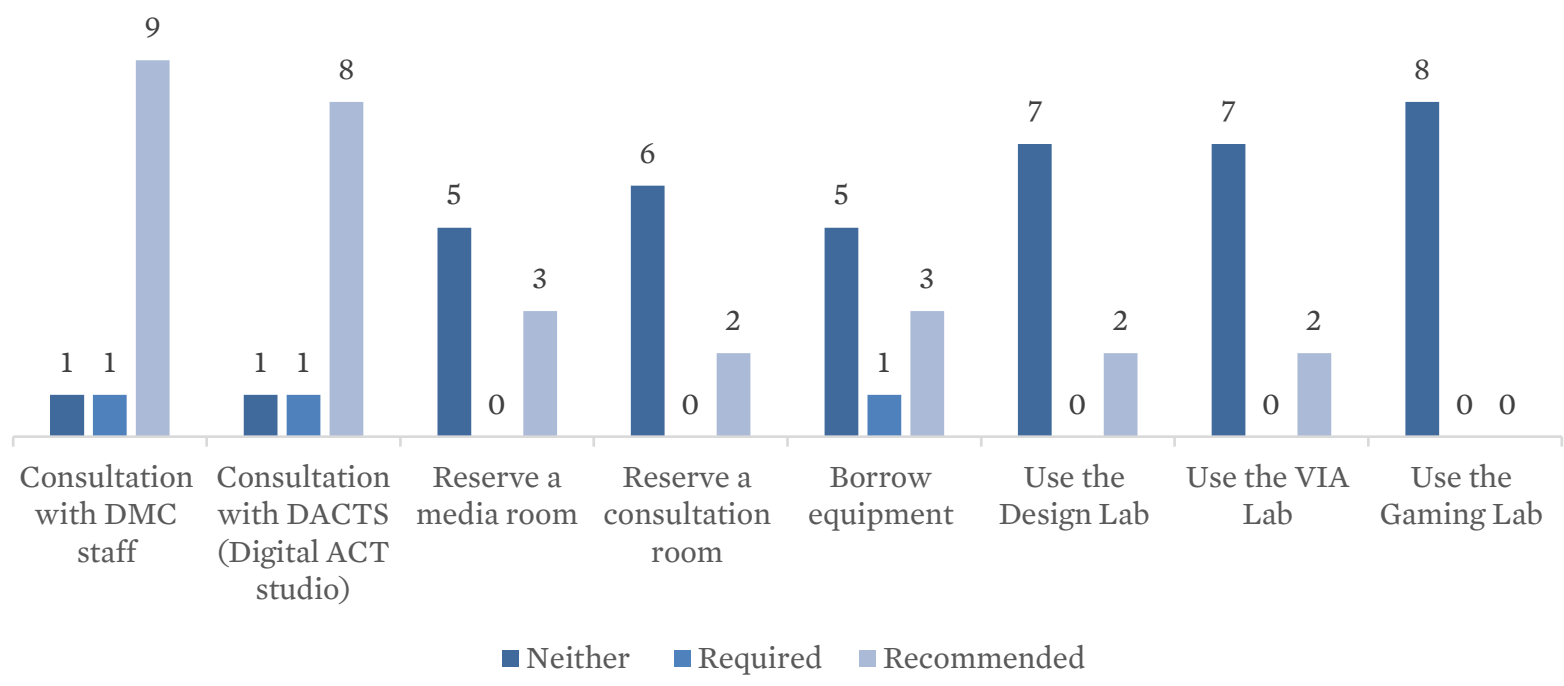

Faculty provided positive feedback about the quality of their students' projects, with the majority indicating that students met or exceeded expectations in most applicable categories:

\section{Did students meet expectations?}

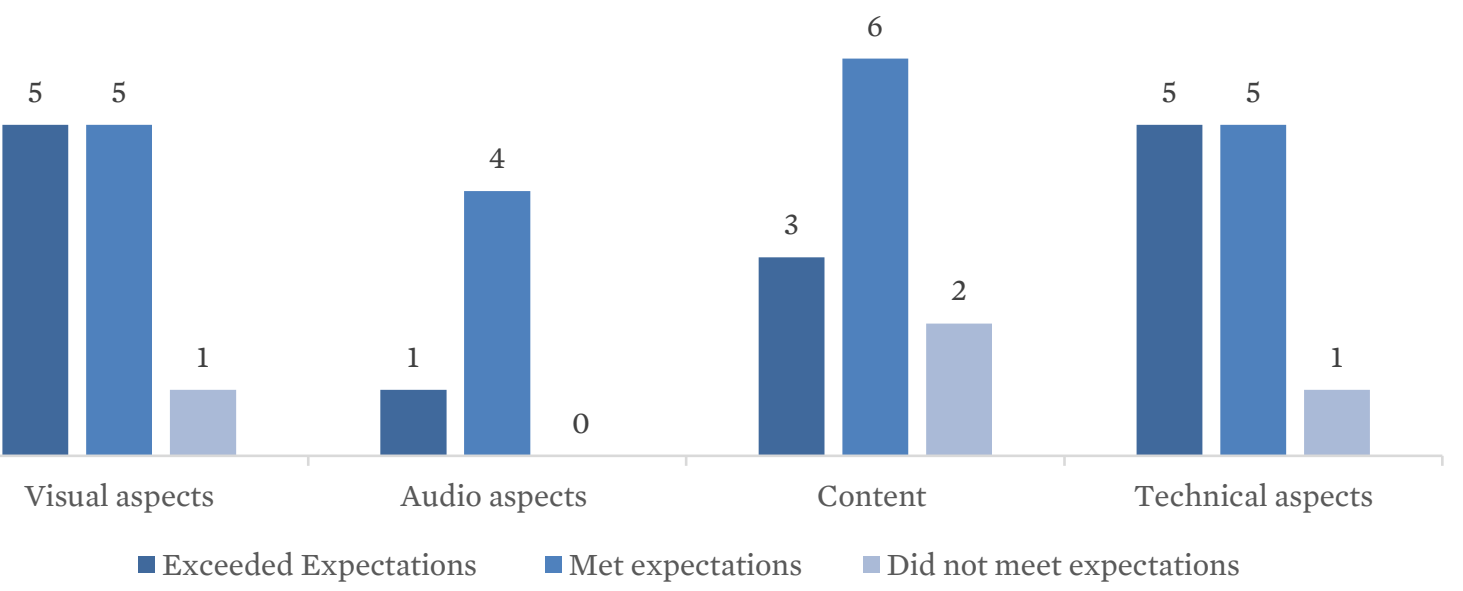


Faculty were also mostly positive about the quality of the presentations provided by DMC staff, with most agreeing that the session was effective or very effective:

\section{Please provide feedback on the instruction session(s) you received from DMC}
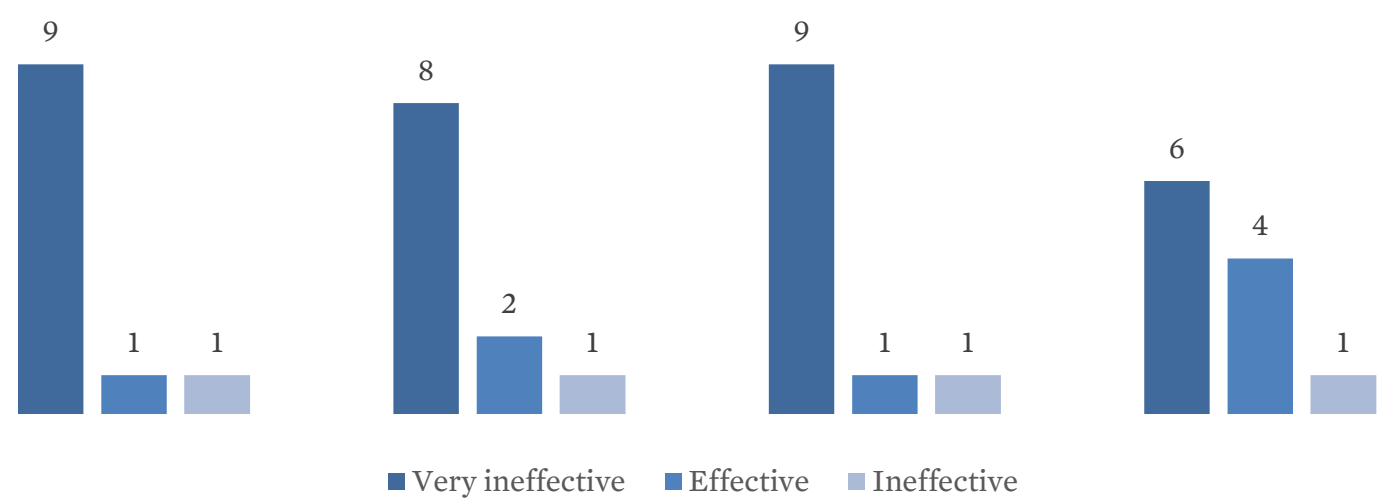

Comments about the instruction sessions included:

"The session with the DMC was central to the success of my students."

"Invaluable to this-I could not teach the class in this way if it weren't for the DMC."

Additional comments included:

"DMC and DACTS staff bent over backwards to support my course and the work of the students."

"One of the best resources for faculty and staff at UNCG!"

\section{Customer Service Survey}

A customer service survey was conducted during several weeks in spring 2018 and fall 2018. The survey used Qualtrics Mobile and was loaded onto an iPad. DMC staff asked customers to complete the survey at the service desk and also roamed the area to ask people sitting in the area to take it. We learned that incentives are not only needed to urge people to take surveys, but also for student employees to remember to conduct it! During the fall survey, student employees were incentivized to administer the survey rather than incentivizing patrons to take the survey. Student employees were charged with soliciting at least one survey per shift. The staff member with the highest amount of surveys submitted for each week of the fall survey won a $\$ 10$ lunch at Chick-fil-a. The result was a noticeable increase in the number of surveys submitted.

Three hundred people completed the survey, which asked what assistance they received, what kind of spaces, technology, or equipment they used, what kind of project they were working on, and to rate their interaction with the staff. Demographic information was also collected, including the subject area of their project and their class standing.

Results show that 30 percent of respondents who needed help with projects were working on a digital project for class. Interestingly, 25 percent were there for general study or to use the computers. Many who 
used the "other" option-indicating they were checking out equipment-indicated that we should have added that as an option.

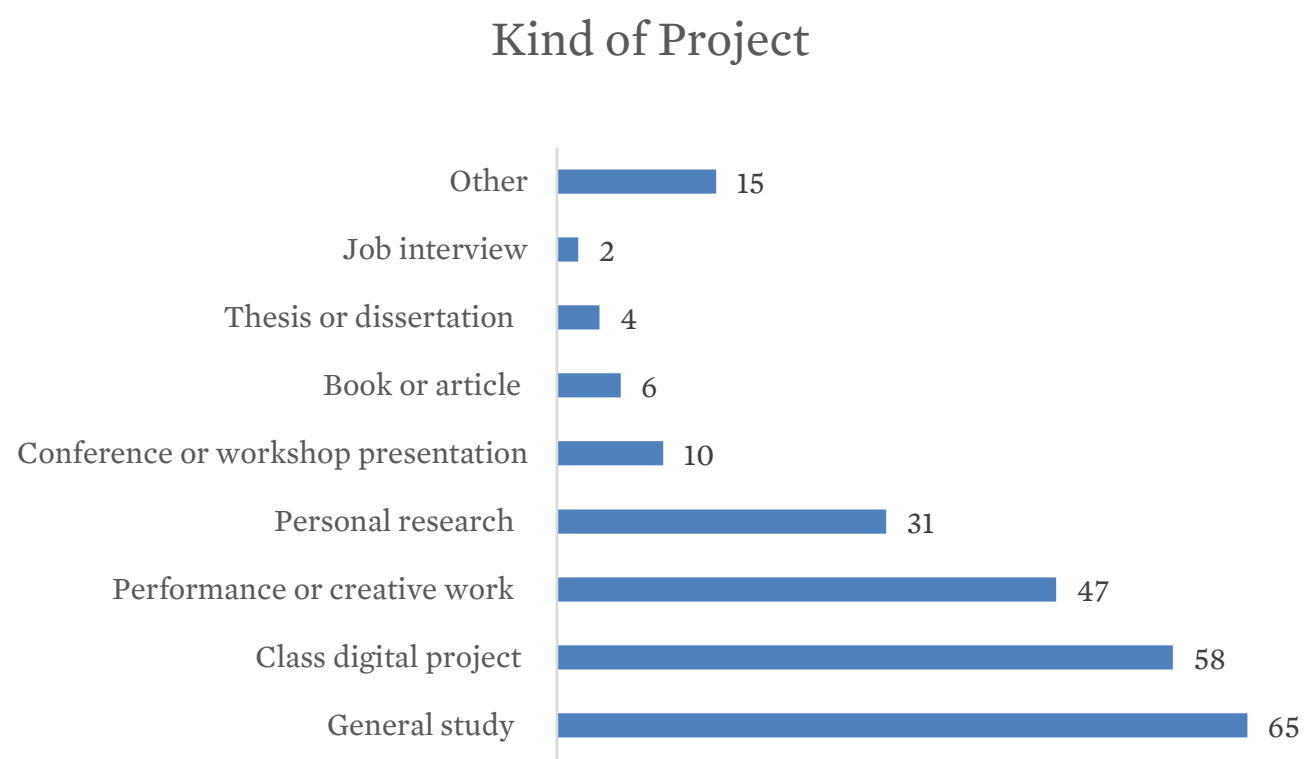

Similarly, when asked what spaces or technology students used, almost half (46\%) were using the area for general study and the computers. These results correspond to those from the next question, which asked what kind of project they were working on. The highest number were using the area for general study, followed by a class digital project, performance or creative work, and personal research.

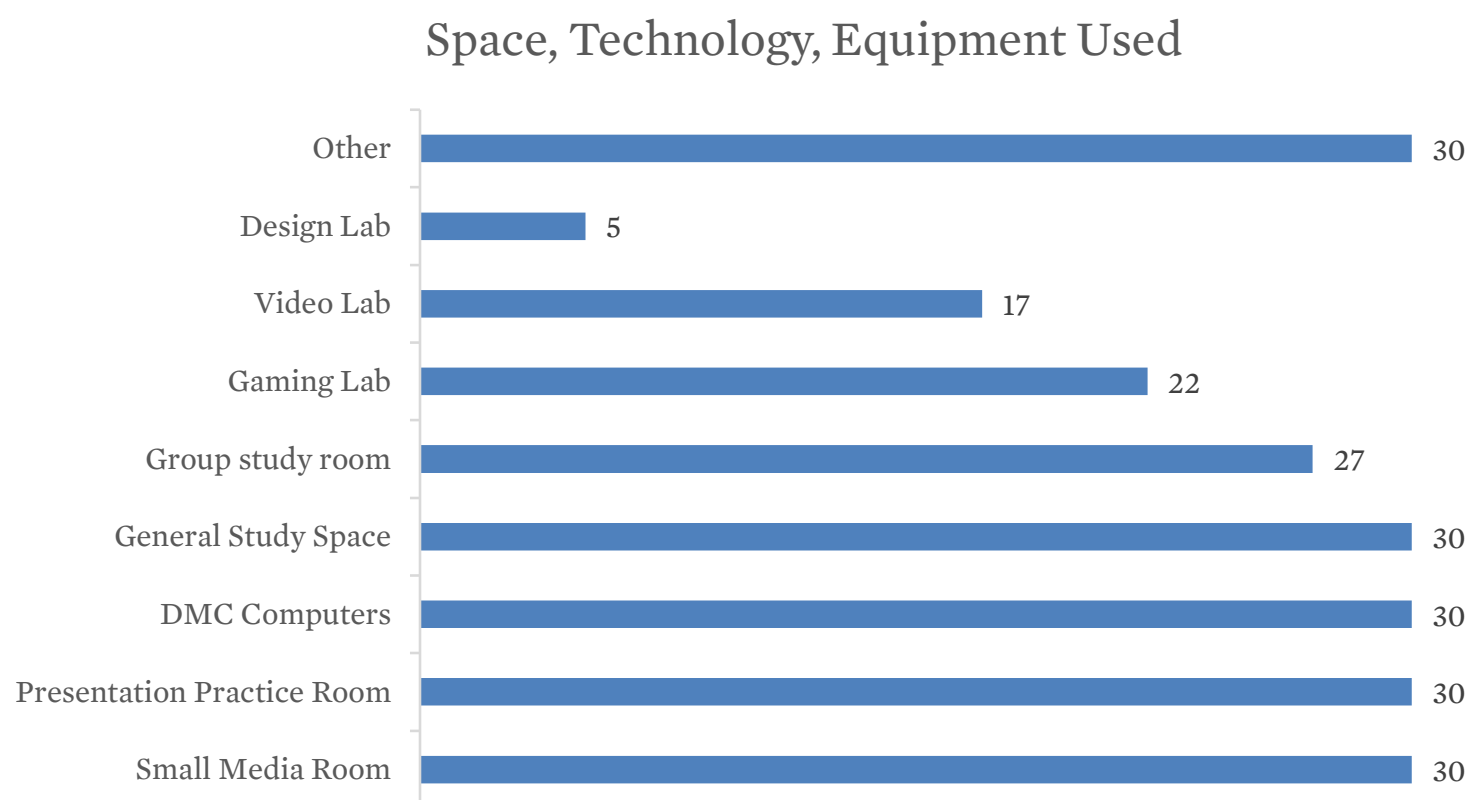


The quality of customer service in the DMC received very positive feedback. Over $80 \%$ responded "agree" or "disagree" to most of the questions asked:

\section{Interaction with Staff}

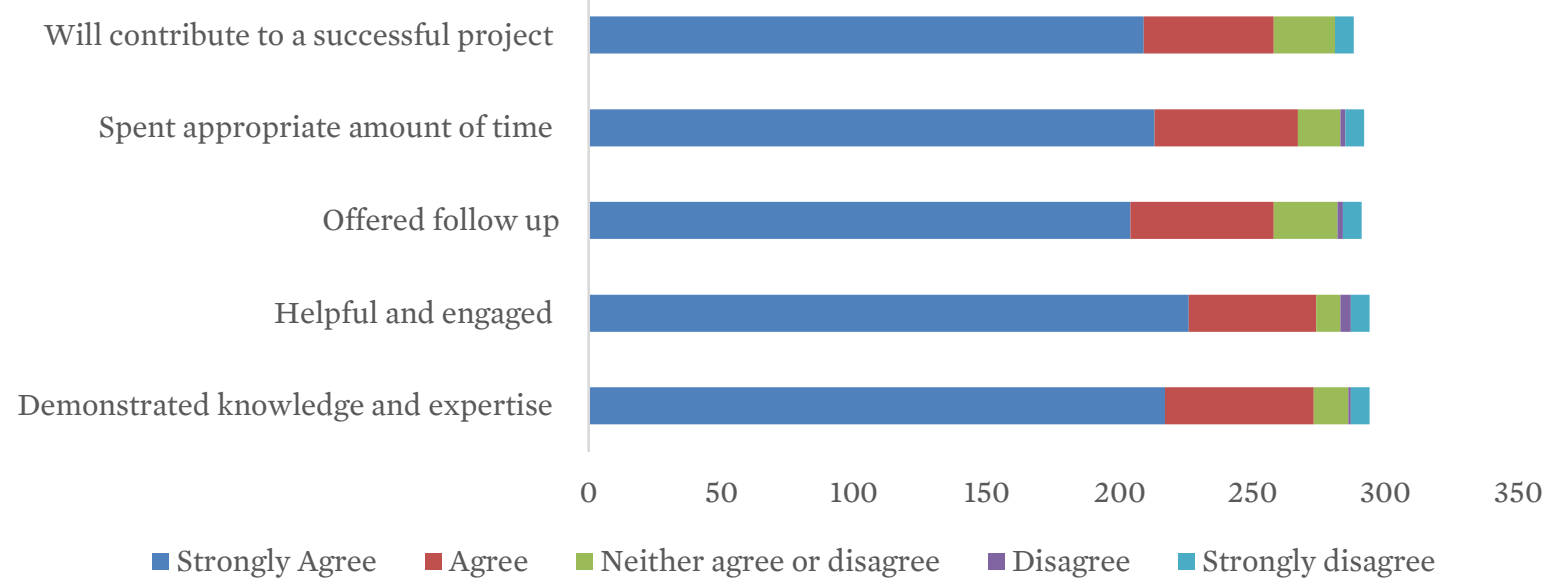

Demographic results indicate that the vast majority (77\%) of DMC users are undergraduates followed by graduate students (16\%). Very few staff or faculty come to the area as general patrons. For subject areas, sciences (21\%) and business students (19\%) were the highest subject areas for the projects, followed by health sciences (14\%) and performing and visual arts (12\%).

General comments and suggestions from customers included:

“Thank you for all of your help! You guys made me feel like being a novice isn’t a bad thing."

"I recommend the DMC and the workers are very helpful when you are having trouble."

"Overall this had been a productive experience."

"It was professional, prompt and helpful. The space needs a new scanner and printer."

\section{Focus Groups}

For the next phase of the study, we conducted focus groups to probe further into information gained in the customer survey and learn the "why" in addition to the "what." We sought to determine students' perceived impact of the DMC services and instruction on their ability to develop quality media projects for a variety of purposes, including class projects, skills for future success, and entrepreneurial efforts. Specifically, we wanted to determine:

- How and why students use the DMC spaces and services

- How DMC spaces and services impact academic success

- How DMC spaces and services impact preparing for careers or graduate school

- What changes, if any, need to be made to improve the DMC spaces and services

We held two focus groups during fall 2018. We recruited participants through a variety of methods including emails, social media, digital signs and posters, and whiteboard notices in the DMC. Participants signed up using a Google form that collected their email so that reminders could be sent. Twelve students attended the first session and four the second. For incentives, we provided pizza and students could also enter a drawing 
for one of four $\$ 25$ gift cards. One person facilitated the focus groups and another took notes. The sessions were also recorded and transcribed.

The participants were primarily undergraduates from all class levels and a wide variety of majors. The question protocol included questions mapped to the research question that asked which spaces they use and how and why they use them, what kind of projects they completed using the DMC services, and how the DMC contributed to their success. (See Appendix I.) We also conducted a "sticky-note" exercise where students wrote a specific project they completed in the DMC on a note and posted on a white board. The following discussion helped drill down how the DMC affects their academic success and helps them learn new skills that they can use in their future careers.

We developed a code book (Appendix II) and three raters hand-coded the focus group transcripts. Each rater highlighted themes they read within the responses of focus group participants according to a color corresponding to that response category (i.e., Technology $=$ Pink, Spaces $=$ Blue, Discovery $=$ Orange, etc.). In many instances, several themes were present in one response. Multiple themes were noted in each response when present. Each rater highlighted responses according to their own interpretation of the transcript. Later, all three raters came together to compare notes and create a master text.

The results of the coding highlighted several trends that were previously only distinguishable through anecdotal observation and participation in the service. Students said they use the DMC "to get my work done," "collaborate," and "get a good grade on the project." For students, the DMC is not only an important destination for study and assistance with media production, it is a choice destination on campus because it provides for a host of functional literacy needs. Five key themes came to the fore:

- The DMC has a knowledgeable staff and congenial service atmosphere.

- Students appreciate its variety of collaboration and group spaces.

- The DMC's variety of furniture and technology are popular.

- Students appreciate the diversity the space engenders.

- Students suggest better marketing of the DMC space and services.

Students stated that they think the DMC's help had a positive impact on their grade. Students cited DMC class instruction and individual assistance as helpful. In several instances, students suggested that the DMC fostered collaboration and creativity in their own work. Several students expressed a desire for more indepth help with tasks related to video production, website design, and Adobe creative design tools. They were glad to have space to film and have troubleshooting assistance during the digital design and production process. They expressly mentioned wanting Apple technology integrated into the space alongside PC platforms, and more digital design classes integrated into their core curriculum.

Students from both groups said they would like to improve "awareness" of the DMC as a space and service. Remarks from both groups also trended toward discovery and wayfinding issues related to the space from outside the library. Students in both groups expressed a desire that the DMC be more visible inside the library. Several participants cited learning about the DMC's services by chance of being in the space or while they needed immediate help. Participants also noted a desire that the library promote the DMC more effectively across campus. Students noted both the space and its services as features of campus life that they would like to become common knowledge.

\section{Conclusions and Next Steps}

This assessment study provided much useful information about the impact and importance of the Digital Media Commons on our students. It is obvious from the assessment results that the DMC offers an effective digital literacy instruction program and learning space that draws students in and keeps them going there. Faculty rate DMC staff instructors and instruction methods positively. Most "agree" or "strongly agree" that direct instruction provided by DMC staff improved their implementation of their multimedia assignments and the quality of the final products their students turned in. Most strongly encouraged their students to 
follow up with the DMC after the group workshop, but few required their students to follow up with our service. Student perceptions of the DMC as a space and service suggest that many of them did in fact follow up to use the DMC for additional direct instruction and as a preferred general study space. The group spaces, small media rooms, double computer screens, white boards, and a variety of furniture provide opportunities for students to both study alone and in groups. Although many of these attributes are available elsewhere in the library, the fact that many of them are in one place seems to appeal to students. In addition to the spaces, the unique services and resources that the DMC provides, including assistance with a variety of media projects and the space and technology for creating them, contribute much to students' success.

The results also indicated that use of the space leans more toward general use than taking advantage of the specialized services and resources. Next steps will include better marketing of the DMC services to increase their visibility. Having the evidence that it contributes to student success will figure into this marketing. Expanding the instructional program will also be a priority. The next staff hire is one that will focus specifically on instruction.

The information from this assessment study will help inform future renovation and addition plans. It is essential to keep the type of learning spaces that the DMC provides. It is also important that the DMC services and resources be more visible than they are now.

-Copyright 2019 Armondo C. Collins and Kathryn M. Crowe

\section{Endnotes}

1. Eun-Young Yoo-Lee, Tae Heon Lee, and LaTesha Velez, "Planning library Spaces and Services for Millennials: An Evidence-Based Approach," Library Management 34, no. 6/7 (2013): 498-511, https://doi.org/10.1108/LM-08-2012-0049.

2. Sara Littlejohn and Kimberly M. Cuny, "Creating a Digital Support Center Foregrounding Multiliteracy," in Cases on Higher Education Spaces; Innovation, Collaboration, and Technology, ed. Russell Carpenter (Hershey, PA: Information Science Reference, 2013): 89-96.

3. Stuart A. Selber, Multiliteracies for a Digital Age, Studies in Writing \& Rhetoric (Carbondale: Southern Illinois University Press, 2004): 24-26.

4. Kimberly M. Cuny, Sara Littlejohn, and Kathryn Crowe, "The Digital Media Commons and the Digital Learning Center Collaborate: The Growing Pains of Creating a Sustainable Flexible Learning Space," in Sustainable Learning Spaces: Design, Infrastructure, and Technology, eds. Russell Carpenter, Reichard Selfe, Shaw Apostel, and Kristi Apostel (Logan, UT: Computers and Composition Digital Press/Utah State University Press, 2015), https://ccdigitalpress.org/sustainable; Lindsay Sabatino, "Fostering Writing Studio Pedagogy in Space Designed for Digital Composing Practices," in Writing Studio Pedagogy: Space, Place, and Rhetoric in Collaborative Environments, eds. Matthew Kim and Russell Carpenter (Lanham, MD: Rowman \& Littlefield, 2017): 178-182.

5. Beth Filar Williams and Michelle Folkman, "Librarians as Makers," Journal of Library Administration 57, no. 1 (2017): 17-35, https://doi.org/10.1080/01930826.2016.1215676.

6. Chelsea DeAngio, and Kathryn Crowe, "Assessing the Digital Media Commons: Evaluating New Library Spaces and Services at UNC Greensboro" (presentation, Southeastern Library Assessment Conference, Atlanta, GA, October 2013), https://scholarworks.gsu.edu/cgi/viewcontent.cgi?article=1005\&context=southeasternlac. 


\section{Appendix I \\ Digital Media Commons Research Question}

Focus Groups

Determine students' perceived impact of the Digital Media Commons services/instruction on their ability to develop quality media projects for a variety of purposes including class projects, interviews, entrepreneurial efforts, and personal interests. These projects can include videos, podcasts, posters, digital presentations, 3D objects, infographics, e-portfolios, and websites.

Determine how and why students use the DMC's spaces and services.

Determine what changes, if any, need to be made to improve the DMC's spaces and services.

Determine how DMCs spaces and services impact academic success.

Determine how DMC spaces and services impact preparing for careers or graduate school.

\section{Focus Group Questions}

1. Which DMC spaces do you usually use and why/how?

2. What DMC technology have you used and why/how?

3. Do you like to use the DMC area? Why? Why not?

4. What kind of projects have you completed with DMC assistance? Have students write these on a sticky note. Sort by type of project. Place notes on a white board for discussion.

Please describe these projects for which you used the DMC. How did the DMC services help you develop a successful project?

5. How has the DMC assistance with these projects contributed to your academic success such as making a better grade in class or learning useful skills to apply to your academic work?

6. How has the DMC assistance helped you with preparing for your career, getting a job or acceptance into graduate school?

7. Are there changes or improvements you'd like to see in the DMC's spaces or services? If so, please explain.

8. Have you ever attended a DMC instructional workshop for a class assignment? Did the instruction improve your ability to complete the assignment successfully? 


\section{Appendix II \\ Digital Media Commons}

Focus Group Code Book

\begin{tabular}{|c|c|c|}
\hline Code & Explanation & Keywords \\
\hline Technology & $\begin{array}{l}\text { References to use of technology, } \\
\text { equipment or software provided in the } \\
\text { DMC }\end{array}$ & $\begin{array}{l}\text { Computers, screens, software, charging } \\
\text { stations, Adobe, Final Cut Pro, MovieMaker, } \\
\text { Tech checkout }\end{array}$ \\
\hline Spaces & $\begin{array}{l}\text { References to furniture and how } \\
\text { students use the DMC spaces }\end{array}$ & $\begin{array}{l}\text { Rooms, furniture, group spaces, individual } \\
\text { spaces study spaces, whiteboards }\end{array}$ \\
\hline Services & $\begin{array}{l}\text { Reference to instruction sessions, } \\
\text { individual assistance, training }\end{array}$ & $\begin{array}{l}\text { Class sessions, training sessions, help, } \\
\text { individual assistance, making videos, PPT, } \\
\text { poster, presentation, DACTS }\end{array}$ \\
\hline Atmosphere & $\begin{array}{l}\text { References to the learning/study } \\
\text { atmosphere in the DMC }\end{array}$ & $\begin{array}{l}\text { Quiet, collaboration, diversity, social aspect, } \\
\text { welcoming, creating community }\end{array}$ \\
\hline Success & $\begin{array}{l}\text { References to perceptions of how DMC } \\
\text { services impact academic or future } \\
\text { career success }\end{array}$ & $\begin{array}{l}\text { Grades, resume, cover letter, skill set, } \\
\text { successful project }\end{array}$ \\
\hline Discovery & $\begin{array}{l}\text { References to how students found or } \\
\text { discovered the DMC }\end{array}$ & Referral, finding the DMC \\
\hline Improvements & $\begin{array}{l}\text { References to how the DMC could be } \\
\text { improved }\end{array}$ & $\begin{array}{l}\text { Suggestions for furniture, software, other } \\
\text { spaces, power }\end{array}$ \\
\hline $\begin{array}{l}\text { General } \\
\text { Comments }\end{array}$ & $\begin{array}{l}\text { General comments about the } \\
\text { University Libraries }\end{array}$ & $\begin{array}{l}\text { Hours, "upstairs," cleanliness, printing, } \\
\text { temperature, reserving a room }\end{array}$ \\
\hline
\end{tabular}

